\title{
Editorial \\ How can we reduce the risk of serious infection for patients with systemic lupus erythematosus?
}

\author{
Diane L Kamen
}

Division of Rheumatology, Medical University of South Carolina, 96 Jonathan Lucas Street, Suite 912, Charleston, South Carolina, SC 29425-2229, USA

Corresponding author: Diane L Kamen, kamend@musc.edu

Published: 28 October 2009

Arthritis Research \& Therapy 2009, 11:129 (doi:10.1186/ar2818)

This article is online at http://arthritis-research.com/content/11/5/129

(c) 2009 BioMed Central Ltd

See related research by Ruiz-Irastorza et al., http://arthritis-research.com/content/11/4/R109

\begin{abstract}
Infection is responsible for approximately $25 \%$ of all deaths in patients with systemic lupus erythematosus (SLE), making it a leading cause of mortality among patients. Ruiz-Irastorza and colleagues, in a recent issue of Arthritis Research \& Therapy, report the clinical predictors of major infections found in a prospective study of patients with SLE. Similar patterns of infection and pathogens as reported in previous studies were seen; what is striking, however, was the protective effect seen with anti-malarial use. Many infections in patients with SLE could be prevented with timely vaccinations, reducing exposure to contagious contacts, screening for latent infections, minimizing exposure to corticosteroids, targeted prophylaxis for high risk patients, and, unless contraindicated, anti-malarial therapy as standard of care.
\end{abstract}

In a recent issue of Arthritis Research \& Therapy, RuizIrastorza and colleagues [1] report the clinical predictors of major infections found in a prospective cohort of patients with systemic lupus erythematosus (SLE) from Spain. The 83 patients with at least one major infection were compared to 166 patients with no major infection history. Major infection is defined as disseminated, affecting deep organs, requiring hospital admission for treatment, or causing death. Their report includes a number of methodological improvements over previous studies of major infections in patients with SLE, including its large size, matched SLE controls and longitudinal design.

The reasons behind the high rate of infections seen among patients with SLE are multi-factorial but many are also modifiable. Impaired immune system defenses can be caused by active disease, SLE-associated dysfunction of both innate and acquired immunity, or by the immunosuppressive medications used to treat SLE. Additionally, patients have greater exposure to infectious pathogens, particularly drug- resistant ones, from proximity to other patients and health care workers during outpatient and/or inpatient visits.

Infection is responsible for approximately $25 \%$ of all deaths in patients with SLE, making it a leading cause of mortality among patients with SLE [2,3]. The prevalence of lifethreatening infections appears to be highest within the first 5 years of disease onset $[2,4]$. Often, the infections that lead to hospitalization and/or death among patients with SLE are caused by common pathogens such as Streptococcus pneumoniae and Haemophilus influenzae, for which effective vaccinations exist [3]. Therapy for patients with SLE has shifted to include more use of biologics such as rituximab and abatacept that increase infection risk in rheumatoid arthritis, but longer patient exposure is needed to determine if this shift has altered infection outcomes in SLE [5].

In line with other reports, Ruiz-Irastorza and colleagues found prednisone use to be associated with infection risk, with each $10 \mathrm{mg}$ per day increase of prednisone increasing the risk of serious infection 11-fold. Similar patterns of infection and pathogens as reported in previous studies were seen; what is striking, however, was the protective effect seen with antimalarial use. Most prior studies of predictors of major infection in SLE did not explicitly look at anti-malarial use and several lumped anti-malarials into the analysis with other immunomodulatory medications. Ruiz-Irastorza and colleagues found that, of the 83 patients with a major infection, 22\% were taking an anti-malarial compared to $77 \%$ of patients matched for time-to-event and age at diagnosis with no major infection history [1]. In a multivariate model that included other potential contributing factors for infection, use of antimalarials (odds ratio $0.09,95 \%$ confidence interval 0.05 to 0.18 ) and the duration in months of anti-malarial treatment

$\mathrm{SLE}=$ systemic lupus erythematosus. 
(odds ratio $0.991,95 \%$ confidence interval 0.984 to 0.999 ) were the strongest predictors of protection against a major infection. The significance persisted after adjustment for potential confounders related to anti-malarial treatment, including markers of SLE severity, since anti-malarials are more likely to be prescribed to patients with milder disease.

Anti-malarials have a unique mechanism of action in that they interfere with antigen processing by raising lysosomal $\mathrm{pH}$ and may prevent apoptotic debris from stimulating and sustaining autoimmunity through inhibition of toll-like receptors 7 and 9 . The anti-malarials are immunomodulatory without being immunosuppressive in that they downregulate the processing of low affinity antigens (for example, self peptides) while preserving the processing of high affinity antigens (for example, foreign peptides) [6]. The benefits of anti-malarials in patients with SLE go beyond preventing infection and include prevention of disease flares and accrual of damage, with some studies also showing a reduction in vascular and thrombotic events and improved survival [7]. A review of evidence published from 95 articles between 1982 and 2007 on the beneficial and adverse effects of anti-malarial drug therapy in SLE concludes that hydroxychloroquine should be given to most patients with SLE during the whole course of the disease, irrespective of severity, and be continued during pregnancy [6].

Even though the immunologic response may be dampened by concomitant immunosuppressive medications, it is best practice to always address immunization status in patients with SLE regardless of their age or other risk factors. In order to achieve the highest immunologic response, influenza and pneumococcus vaccines should be given routinely and preferably during a time of less intense immunosuppression and disease activity. Fears of certain vaccinations precipitating SLE exacerbation are based on only weak evidence [8], while there is excellent evidence that non-live vaccines are safe and prevent infectious complications among patients with SLE. Guidelines are in place recommending the influenza vaccine and pneumococcus vaccine for patients with rheumatoid arthritis but similar guidelines have not been developed for SLE. With the exception of the live attenuated vaccines, other vaccinations should be kept up-to-date in patients with SLE.

Caring for patients with SLE includes commonsense measures such as timely vaccinations, reducing exposure to contagious contacts, screening for latent infections such as Mycobacterium tuberculosis, minimizing exposure to corticosteroids, and targeted re-activation and infection prophylaxis for high risk patients. Based on an estimated prevalence of $29 \%$ for serious infections among patients with SLE and the findings of Ruiz-Irastorza and colleagues, the number needed to treat with an anti-malarial to prevent one major infection is only 4. Growing evidence, now including protection against major infections, supports the universal use of anti-malarial drugs as standard of care for all patients with SLE without contraindications.

\section{Competing interests}

The author declares that they have no competing interests.

\section{References}

1. Ruiz-Irastorza G, Olivares N, Ruiz-Arruza I, Martinez-Berriotxoa A, Egurbide MV, Aguirre C: Predictors of major infections in systemic lupus erythematosus. Arthritis Res Ther 2009, 11:R109.

2. Cervera R, Khamashta MA, Font J, Sebastiani GD, Gil A, Lavilla P Mejía JC, Aydintug AO, Chwalinska-Sadowska H, de Ramón E, Fernández-Nebro A, Galeazzi M, Valen M, Mathieu A, Houssiau F, Caro N, Alba P, Ramos-Casals M, Ingelmo M, Hughes GR; European Working Party on Systemic Lupus Erythematosus: Morbidity and mortality in systemic lupus erythematosus during a 10-year period: a comparison of early and late manifestations in a cohort of 1,000 patients. Medicine (Baltimore) 2003, 82: 299-308.

3. Goldblatt F, Chambers S, Rahman A, Isenberg DA: Serious infections in British patients with systemic lupus erythematosus: hospitalisations and mortality. Lupus 2009, 18:682-689.

4. Abu-Shakra M, Urowitz MB, Gladman DD, Gough J: Mortality studies in systemic lupus erythematosus. Results from a single center. I. Causes of death. J Rheumatol 1995, 22:12591264 .

5. Furst DE, Keystone EC, Kirkham B, Kavanaugh A, Fleischmann R, Mease P, Breedveld FC, Smolen JS, Kalden JR, Burmester GR, Braun J, Emery P, Winthrop K, Bresnihan B, De Benedetti F, Dörner T, Gibofsky A, Schiff MH, Sieper J, Singer N, Van Riel PL, Weinblatt ME, Weisman MH: Updated consensus statement on biological agents for the treatment of rheumatic diseases, 2008. Ann Rheum Dis 2008, 67(Suppl 3):iii2-25.

6. Ruiz-Irastorza G, Ramos-Casals M, Brito-Zeron P, Khamashta MA: Clinical efficacy and side effects of antimalarials in systemic lupus erythematosus: a systematic review. Ann Rheum Dis 2009, [Epub ahead of print].

7. Alarcon GS, McGwin G, Bertoli AM, Fessler BJ, Calvo-Alen J, Bastian HM, Vila LM, Reveille JD: Effect of hydroxychloroquine on the survival of patients with systemic lupus erythematosus: data from LUMINA, a multiethnic US cohort (LUMINA L). Ann Rheum Dis 2007, 66:1168-1172.

8. Millet A, Decaux O, Perlat A, Grosbois B, Jego P: Systemic lupus erythematosus and vaccination. Eur J Intern Med 2009, 20: 236-241. 